\title{
Radius Distal Uç Kırığı Volar Plaklama Sonrası Fizyoterapi Uygulanan Hastalarda Radyolojik Ölçümler İle Fonksiyonel Ölçümler İlişkili Midir?
}

\section{Do Radiological and Functional Outcomes Correlated for Patients Receiving Physiotherapy After Volar Plating of Distal Radius Fracture?}

\author{
Murat TOMRUK ${ }^{\mathrm{a}}$, Nihal GELECEK ${ }^{\mathrm{b}}$, Onur BAŞÇI ${ }^{\mathrm{c}}$, Mustafa Hulisi ÖZKAN ${ }^{\mathrm{d}}$
}

ÖZ Amaç: Radius distal uç kırığına bağlı volar plaklama yapılan hastaların radyolojik ölçümleri ile eklem hareket açıklıkları, kavrama kuvveti ve fonksiyonel sonuçları arasındaki ilişkiyi araştırmaktı. Gereç ve Yöntem: Çalışmaya radius distal uç kırığı sonrası volar plaklama yapılan ve 12 haftalık süpervize fizyoterapi programını tamamlayan 31 hasta (18 kadın, 13 erkek) alındı. Hastaların radyolojik ölçümleri postoperatif 1 . haftada içinde çekilen direkt grafileri üzerinde yapıldı. Volar tilt, radiyal uzunluk, radiyal inklinasyon ve ulnar varyans değerleri kaydedildi. Postoperatif 12 haftada hastaların el bileği ve önkol eklem hareket açılıkları, kavrama kuvveti ve fonksiyonel düzeyleri (Hasta Bazlı El Bileği Değerlendirme Anketi "PRWE" ve Kol, Omuz ve El Yaralanması Anketi "DASH") ölçüldü. Radyolojik sonuçlar ile fonksiyonel sonuçlar arasındaki ilişkiyi belirlemek için Spearman Korelasyon Analizi yapıldı. Bulgular: Radyolojik ölçümlerden "ulnar varyans değeri" ile PRWE ağrı skoru ve PRWE toplam skoru arasında pozitif yönde anlamlı ilişki belirlendi (sırasıyla $\mathrm{p}=0.030, \mathrm{r}=0.443$; $\mathrm{p}=0.039$, $\mathrm{r}=0.424)$. Diğer radyolojik ölçümler ile hiçbir parametre arasında istatististiksel olarak anlamlı korelasyon yoktu ( $\mathrm{p}>0.05)$. El bileği fleksiyon ve ekstansiyon dereceleri de kavrama kuvveti ile (sirasiyla, $r=0,660, r=0.619$ ) ve PWRE fonksiyon skorları ile (sırasıyla, $\mathrm{r}=-0.497, \mathrm{r}=-0.520$ ) anlamlı korelasyon gösterdi $(\mathrm{p}<0.05)$. Sonuç: Bu çalışma radius distal uç kırı̆̆ı sonrası volar plaklama yapılan ve fizyoterapi programına alınan hastalarda, radyolojik ölçümlerden yalnızca ulnar varyans değerinin fonksiyonel sonuçları etkilediğini göstermiştir. Daha kesin sonuçlar için farklı redüksiyon tiplerinde ve farklı hasta sayılarında çalışmalara ihtiyaç bulunmaktadır.

Anahtar kelimeler: Radius kırıkları, fizyoterapi, radyolojik, fonksiyonel, sonuç.

ABSTRACT Objective: The aim of this study was to investigate the relationships between radiological outcomes and range of motions, grip strength, and functional outcomes in patients receiving physiotherapy after volar plating of distal radius fracture. Methods: 31 patients (18 female, 13 male) who completed the 12-week supervised physiotherapy program after volar plating of distal radius fracture were enrolled. Radiographic measurements of the patients were made by direct radiographs taken at 1 week postoperatively. Volar tilt, radial length, radial inclination and ulnar variance values were recorded. Wrist and forearm range of motions, grip strength and functional level (Patient Rated Wrist Evaluation "PRWE" and Disabilities of Arm, Hand and Shoulder "DASH") were assessed at the end of the 12-week physiotherapy program postoperatively. Functional scores of the wrist, grip strength and range of motions were measured. Spearman's correlation analysis was performed to determine the relationship between radiological and functional outcomes. Results: Significant positive correlations were found between "ulnar variance value", which is one of the radiological measurements, and PRWE pain score and PRWE total score ( $\mathrm{p}=0.030, \mathrm{r}=0.443 ; \mathrm{p}=0.039, \mathrm{r}=0.424$, respectively). There was no statistically significant correlation between other radiological measurements and none of the parameters ( $\mathrm{p}>0.05)$. Wrist flexion and extension were significantly correlated with grip strength $(\mathrm{r}=0,660, \mathrm{r}=0.619$, respectively) and PRWE function score $(\mathrm{r}=-0.497, \mathrm{r}=-0.520$, respectively). Conclusion: This study showed that only ulnar variance value has an effect on functional outcomes in patients receiving physiotherapy after volar plating of distal radius fracture. For more precise results, studies with various reduction types and different number of patients were needed.

Keywords: Radius fracture, physiotherapy, radiological, functional, outcome.

\section{Giriş}

Radius distal uç (RDU) kırığı en sık karşılaşılan kırık olup (1), tüm kırıkların \%14’ünü (2), acil servise gelen kırıkların ise altıda birinden fazlasını oluşturur (3). RDU kırı̆̆ının cerrahi

tedavi yöntemlerinden volar plaklama, iyi redüksiyon ve erken fonksiyonel tedavilere olanak sağlaması sebebiyle en sık tercih edilen yöntemdir. Kilitli plakların kullanımı RDU

Geliş Tarihi/Received:24-01-2018/ Kabul Tarihi/Accepted:01/04/2018

${ }^{a} U z m$. Fzt. Dokuz eylül Üniversitesi Fizyoterapi ve Rehabilitasyon Yüksekokulu, murat.tomrukdu.edu.tr, ORCID:0000-00023941-816X

${ }^{b}$ Prof. Dr. Dokuz eylül Üniversitesi Fizyoterapi ve Rehabilitasyon Yüksekokulu, nihal.gelecek@edu.tr, ORCID:0000-0003-1780-2520

${ }^{c}$ Yrd Doç. Dr. Dokuz Eylül Üniversitesi Tıp Fakültesi Cerrahi Tıp Bilimleri Bölümü, Ortopedi Ve Travmatoloji Anabilim Dalı, omur.basci@ deu.edu.tr, ORCID: 0000-0003-1689-0346

d Prof. Dr. Dokuz Eylül Üniversitesi Tıp Fakültesi Cerrahi Tıp Bilimleri Bölümü, Ortopedi Ve Travmatoloji Anabilim Dalı, mustafa.ozkan@deu.edu.tr, ORCID:0000-0001-9274-3060

Sorumlu yazar /correspondence: Uzm Fzt. Murat TOMRUK, murat.tomrukdu.edu.tr

HSP 2018;5 (3):424-434 
kırığının cerrahi tedavisinde standart bir prosedür haline gelmiştir (4). Bu hastalarda cerrahi sonrası el bileği etkilenimine bağlı uzun dönem özürlülük riski oldukça yüksek olduğundan, postoperatif rehabilitasyon bütünleyici tedavi yaklaşımının ayrılmaz bir parçasıdır $(5,6)$. Postoperatif dönemde görülen kompleks bölgesel ağr1 sendromu Tip 1 (KBAS-1), osteoartroz, karpal tünel sendromu, parmak sertliği, yanlış kaynama gibi komplikasyonların (7) önlenmesi için etkili fizyoterapi ve rehabilitasyon programlarına ihtiyaç vardır $(8,9)$.

RDU kırığının tedavisinde amaç el bileği anatomisi ve fonksiyonunun normale en yakın biçimde yeniden kazanılmasıdır (10). Anatomik restorasyon genelde radyolojik ölçümlerle, fonksiyonel restorasyon ise fonksiyonel ölçümlerle değerlendirilmektedir (11-14). El bileği ve önkol eklem hareket açıklıkları ve el kavrama kuvvetinin yanında birtakım skorlama sistemleri, elin fonksiyonel düzeyini belirlemek amacıyla kullanılmaktadır. Literatürde el bileği fonksiyonu ve özürlülüğü değerlendirmede en sık kullanılan anketler "Hasta Bazlı El Bileği Değerlendirmesi ("HBEBD" Patient Rated Wrist Evaluation)" ve "Kol, Omuz ve El Yaralanması Anketi (Disabilities of Arm, Shoulder and Hand "DASH")"dir.

RDU kırıkları sonrası tedavinin başarısını veya fonksiyonel sonuçları etkileyen birçok faktör bulunmaktadir. Postoperatif fizyoterapi uygulamaları (ev programları, süpervize programlar) bunlardan biridir (8). Literatürde yaygın görüş, RDU kırığ1 olan hastalarda iyi anatomik restorasyonun iyi fonksiyonel sonuçlara yol açacağıdır (15-17). Bu yüzden radyolojik ölçümlerle fonksiyonel ölçümler arasında ilişki olması beklenmektedir. Ancak yapılan çalışmaların bazılarında bu ilişki bulunurken (1719), bazılarında ise ilişki saptanmamıştır (12, 2022). Ayrıca literatürdeki çalışmaların çoğu opere olmayan RDU kırıklarında bu ilişkiyi incelemiştir. Opere hastalarda bu ilişkiyi inceleyen yalnızca bir çalışmada bulunmaktadır, ancak bu çalışmada da hastalara postoperatif fizyoterapi programı uygulanmamıştır (13). Bu çalışmanın amacı RDU kırı̆̆ı volar plaklama sonrası fizyoterapi uygulanan hastalarda radyolojik ölçümler ile fonksiyonel ölçümler arasındaki ilişkinin araştırılmasıdır.

\section{Gereç ve Yöntem}

Prospektif olarak düzenlenen çalışma Ekim 2015 - Ağustos 2017 yılları arasında, Ortopedi ve Travmatoloji Anabilim Dalı'na RDU kırı̆̆1 sonras1 aynı cerrahi ekip tarafindan volar plaklama yapılan, 18 yaş üstü, gönüllü hastalarda yapıld1. Etkilenen tarafta daha önceden geçirilen ön kol kırı̆̆ı ve eş zamanlı kontralateral üst ekstremitede de kırı̆̆ 1 olanlar ile inflamatuar eklem hastalıklarına sahip olanlar çalışmadan çıkarıldı. Volar plaklama cerrahisi sonrası postoperatif 1. günde hastalara ulaşıldı, hastaların demografik ve klinik özelliklerini içeren ilk kayıtları alındı. Tüm hastalar postoperatif birinci günden itibaren fizyoterapi programına alındı ve taburcu olduktan sonra da 12 hafta süresince haftada iki kez olarak planlanan ve bir seansı 45$60 \mathrm{dk}$ süren fizyoterapi programı hastalara uyguland. Aktif el bileği hareketlerine postoperatif birinci haftanın sonunda alçı atel çıkarıldıktan sonra başlandı. Sekizinci haftada dirençli egzersiz eğitimine başlandı. Postoperatif 12. haftada tüm hastaların fonksiyonel ölçümleri yapıldı. Radyolojik ölçümler ise postoperatif birinci hafta içinde yapıldı.

Çalışmanın etik kurul onayı, ilgili üniversitenin Etik Kurulu'ndan, 10.09.2015 tarih ve 2258-GOA protokol numaralı 2015/21-04 karar numarası ile alındı. Araştırmaya alınmadan önce tüm bireylere araştırma hakkında sözlü ve yazılı bilgi verildi ve "Bilgilendirilmiş Gönüllü Olur Formu” imzalatılıp, katılımcıların onamları alındi.

\section{Veri Toplama Araçları}

Fonksiyonel Sonuçlar

Çalışmada fonksiyonel sonuç ölçümleri olarak el bileği fonksiyonu, özürlülük, kavrama kuvveti ve eklem hareket açıklıkları değerlendirildi.

Hasta Bazlı El Bilĕgi Değerlendirme Anketi $(H B E B D)$ : HBEBD el bileği ağrısının şiddetini ve günlük yaşam aktivitelerindeki özürlülük düzeyini ölçen 15 sorudan oluşur. İki alt bölümü vardır. Ağrı alt bölümü ağrı şiddeti ve frekansı üzerine dört sorudan oluşurken, Fonksiyon alt bölümü ise spesifik aktiviteler üzerine altı 
sorudan ve günlük aktiviteler üzerine dört sorudan oluşur. Her soruya $0-10$ arasında yanıt verilir ve skorlanır. Toplam skor 100 üzerinden hesaplanır. Yüksek skorlar ağrı ve özürlülük düzeyinin fazla olduğunu gösterir (23). Anketin ülkemizdeki geçerliliği ve güvenilirliği Öztürk ve arkadaşları tarafından yapılmıştır (24).

Kol, Omuz ve El Yaralanması Anketi (Disabilities of Arm, Shoulder and Hand "DASH"): DASH hastaların kendilerinin doldurduğu, bölgeye spesifik bir ankettir. Üst ekstremitesinde bir veya daha fazla muskuloskeletal hastalığı bulunan hastalarda fiziksel fonksiyonu ve semptomları sorgulayan 30 maddeden oluşmaktadır. Her madde beşli Likert-tipi olarak oluşturulmuştur. 30 soru için tüm cevaplara verilen değerler basit olarak toplanır ve ortalamaları alınır, böylece 5 üzerinden bir puan elde edilir. Bu puandan daha sonra 1 çıkartılıp 25 ile çarpılır ve 100 üzerinden bir puana dönüştürülür. Toplam puan 0 (özürlülük yok) ile 100 (çok ağır özürlülük) arasında olup, yüksek puan yüksek özürlülük düzeyini göstermektedir (25). Anketin ülkemizdeki geçerliliği ve güvenilirliği Düger ve arkadaşları tarafından yapılmıştır (26).

Hidrolik El Dinamometresi: El kavrama kuvvetinin ölçümünde Amerikan El Terapistleri Derneği (AETD) tarafından önerilen ve birçok çalışmada geçerlilik ve güvenirliği yüksek bulunan ve bu nedenle de altın standart olarak kabul edilen "Hidrolik el dinamometresi (The North Coasttm Medical Precision Instruments, Hydraulic Hand Dynamometer, Seri Numarasi: 07060775)" kullanıld1. El kavrama kuvvetinin ölçümü AETD tarafindan önerilen standart pozisyon olan; kalça ve diz $90^{\circ}$ fleksiyonda olacak biçimde oturma pozisyonunda, omuz addüksiyonda ve nötral rotasyonda, dirsek $90^{\circ}$ fleksiyonda, ön kol mid-rotasyonda ve destekli, el bileği nötralde ve $0-15^{0}$ ulnar deviasyonda olacak şekilde yapıldı (27). Hastadan dinamometreyi bütün gücüyle sıkması ve en az üç saniye tutması istendi. Ölçüm ilk olarak etkilenmemiş taraf ekstremitede yapıldı. Toplamda üç ölçüm yapıldı ve üç ölçüm içinden en yüksek değer kg cinsinden kaydedildi (28). Ölçümler sağlam taraf elin kavrama kuvveti yüzdesi (\%) cinsinden hesapland1.

Evrensel Gonyometre: El bileği ve radioulnar eklemlerin hareket açıklıklarını ölçmek için "Evrensel Gonyometre (Whitehall Manufacturing Hydrotherapy and Health Care Products Goniometer)" kullanıldı. Her iki üst ekstremitenin el bileği fleksiyonu ve ekstansiyonu, ön kol supinasyonu ve pronasyonu, el bileği radial ve ulnar deviasyonları aktif olarak ölçüldü. Ölçümler sağlam taraf elin hareket açıklığı yüzdesi (\%) cinsinden hesapland1.

$\underline{\text { Radyolojik Ölçümler }}$

Postero-anterior ve Lateral Direkt Grafi: Hastaların radyolojik ölçüm sonuçları posterioanterior ve lateral direkt grafi görüntülemelerinden yapıld1. "Sectra Workstation IDS7, Sürüm 18.2.18.4066" programı kullanılarak açılar ve uzunluklar hesapland1. Volar tilt, radial uzunluk, radial inklinasyon ve ulnar varyans değerleri kaydedildi (29).

Volar tilt: Lateral grafide radiusun anterior ve posterior uçlarını birleştiren doğru ile radiusun uzun eksenine çizilen dik çizgi arasındaki açıdır. Normal sinirları $0^{\circ}-22^{\circ}$ arasinda olup, ortalama $11^{\circ}-12^{\circ}$ dir $(29,30)$ (Şekil 1).

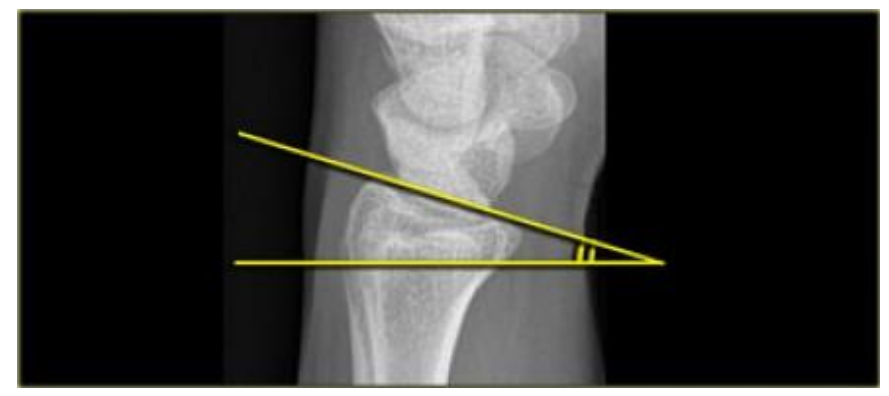

Şekil 1. Volar tilt

Radial uzunluk: Posteroanterior (PA) radyografide radial stilodin ucundan ve ulna başının eklem yüzünden geçen, birbirine paralel iki çizgi arasındaki mesafedir. Normal sınırları 8$18 \mathrm{~mm}$ arasinda olup, ortalama 11-12 mm'dir (29, 30) (Şekil 2). 


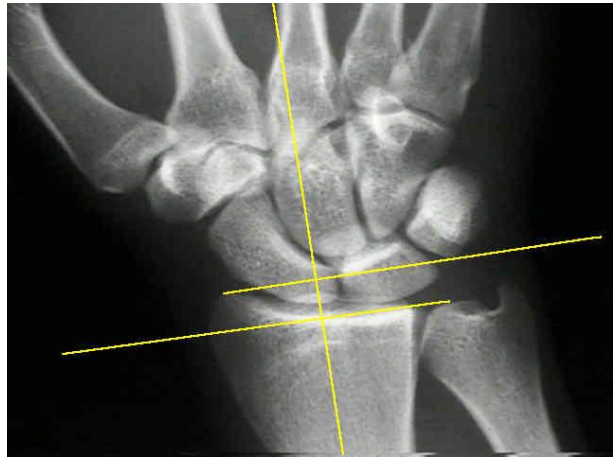

Şekil 2. Radial uzunluk

Radial inklinasyon: PA radyografide radial stiloidin ucu ve DRUE'nin radial kisminı birleştiren çizgi ile radiusun uzun eksenine çizilen dik çizgi arasındaki açıdır. Normal sınırları $13^{\circ}$ $30^{\circ}$ arasinda olup, ortalama $22^{\circ}-23^{\circ}$ dir $(29,30)$ (Şekil 3).

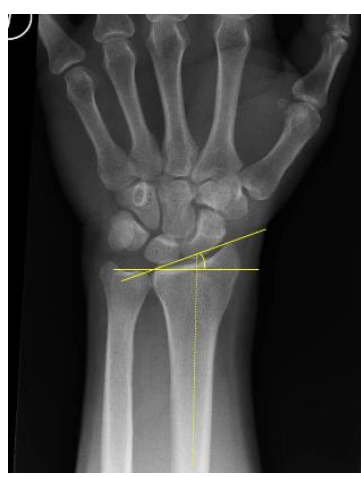

Şekil 3. Radial inklinasyon

Ulnar varyans: Radiusun lunat faseti ile ulna başının eklem yüzü arasındaki vertikal mesafedir. Normalde bu iki yapı yaklaşık olarak aynı mesafede olup, normal anatomik varyans $0 \pm 2$ mm’ dir $(29,30)$ (Şekil 4).

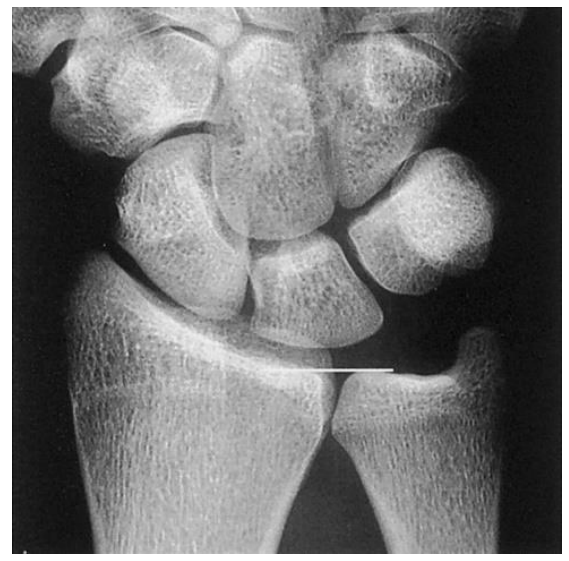

Şekil 4. Ulnar varyans
Radyolojik olarak yeterli redüksiyon (ya da iyi radyolojik sonuç) kriterleri Nana ve ark. (31) ve Shauver ve ark.'nın (13) belirttiği volar tilt $<20^{\circ}$, radial inklinasyon açısı $>15^{\circ}$, pozitif ulnar varyans $<5 \mathrm{~mm}$ ve radial uzunluk $>10 \mathrm{~mm}$ olarak kabul edildi. $\mathrm{Bu}$ kriterlerden herhangi birine uymayan radyolojik değere sahip bireylerde yetersiz redüksiyon varlığ 1 kabul edildi.

\section{İstatistiksel Analiz}

Elde edilen verilerin analizi "IBM SPSS 25.0 for Windows (International Business Machines Statistical Package for the Social Sciences Inc; Chicago, IL, ABD)" programıla yapıldı. Verilerin normal dağılıma uygunluğunun tespiti için "Shapiro Wilk Testi" kullanıldı. Bazı verilerde normal dağılım görülmediği için nonparametrik testler uyguland. Sayısal veriler ortanca, minimum ve maksimum değerler ve çeyrekler arası uzaklık ile ifade edildi. Kategorik veriler $\mathrm{n}(\%)$ şeklinde gösterildi. Yetersiz redüksiyon olan ve olmayan grupların ölçümlerini karşılaștırmada Mann-Whitney U Testi kullanıldı. Parametreler arası ilișki düzeyi Spearman korelasyon analizi kullanılarak yapıldı. Tüm analizlerde $p<0.05$ (iki yönlü) değerler istatistiksel olarak anlamlı kabul edildi.

\section{Bulgular}

RDU kırığ1 olan ve volar plaklama yöntemi ile redüksiyonu yapılan toplam 49 hastanın postoperatif 1. gün değerlendirmeleri yapıld1. Ancak dişlanma kriterlerine sahip olan, tedavi ve kontrollere düzenli katılmayan hastalar çıkarıldıktan sonra 31 hasta ile çalışma tamamland. Hastaların \%58.1'i kadın $(n=18)$, $\% 41.9$ 'u erkekti $(n=13)$. Hastaların demografik özellikleri ile klinik özellikleri Tablo 1 ve 2'de verildi.

Hastaların yaş ortancası (min-maks) 52 (23-76) idi. Hastaların yaşı el bileği ekstansiyonu ve kavrama kuvveti ile negatif yönde anlamlı ilişki gösterirken (sırasıyla $\mathrm{p}=0.014, \mathrm{r}=-0.496$; $\mathrm{p}=0.009$, r=-0.524), HBEBD ağrı skoru, HBEBD fonksiyon skoru, HBEBD toplam skoru ve DASH skoru ile pozitif yönde anlamlı ilişki gösterdi (sirasiyla $\mathrm{p}=0.031, \mathrm{r}=0.440 ; \mathrm{p}<0.001, \mathrm{r}=0.738$; $\mathrm{p}=0.001, \mathrm{r}=0.621 ; \mathrm{p}=0.002, \mathrm{r}=0.596)$. 
Tablo 1. Hastaların demografik ve klinik özelliklerine göre dağılımları

\begin{tabular}{llcc}
\hline Özellikler & & $\mathrm{n}$ & $\%$ \\
& & & \\
\hline Cinsiyet & Kadın & 18 & 58.1 \\
& Erkek & 13 & 41.9 \\
\hline Eğitim & İlkokul & 8 & 25.8 \\
Durumu & Ortaokul & 4 & 12.9 \\
& Lise & 6 & 19.4 \\
& Lisans & 8 & 25.8 \\
& Lisansüstü & 5 & 16.1 \\
\hline Medeni & Bekar & 4 & 12.9 \\
Durum & Evli & 24 & 77.4 \\
& Dul & 3 & 9.7 \\
\hline Mesleki & Çalışmıor & 8 & 25.8 \\
Durum & Çalış1yor & 18 & 58.1 \\
& Emekli & 5 & 16.1 \\
\hline Dominant & Sağ & 30 & 96.8 \\
Taraf & Sol & 1 & 3.2 \\
\hline Yaralanan & Sağ & 11 & 35.5 \\
Taraf & Sol & 20 & 64.5 \\
\hline Anestezi Tipi & Genel & 20 & 64.5 \\
& Lokal & 11 & 35.5 \\
\hline Kemik & Normal & 13 & 41.9 \\
Kalitesi* & Osteopenik & 14 & 45.2 \\
& Osteoporotik & 4 & 12.9 \\
\hline Redüksiyon & Yeterli & 25 & 80.6 \\
& Yetersiz & 6 & 19.4 \\
\hline * Kemik mineral & yoğunluğu ölçümü̈ dansitometri T-spine \\
değerine & göre & (normal>-1.0, & $-1.0>$ osteopenik>-2.5, - \\
2.5>osteoporotik) belirlenmistir & & \\
& & &
\end{tabular}

Çalışmanın sonuçlarına göre radyolojik ölçümlerden "ulnar varyans değeri" ile HBEBD ağr1 skoru ve HBEBD toplam skoru arasında pozitif yönde anlamlı ilişki belirlendi (sırasıyla $\mathrm{p}=0.030, \mathrm{r}=0.443 ; \mathrm{p}=0.039, \mathrm{r}=0.424)$. Volar tilt, radial inklinasyon, radial uzunluk ölçümleri ile kavrama kuvveti, eklem hareket açıklığı ve fonksiyonel skorlar arasındaki korelasyonların zayıf ve istatistiksel olarak anlamlı olmadığ görüldü ( $\mathrm{p}>0.05$ ) (Tablo 3).

Eklem hareket açıklığı ölçümlerinden "el bileği fleksiyonu" ile el kavrama kuvveti arasında pozitif yönde anlamlı ( $\mathrm{r}=0.660)$, HBEBD ağr skoru ( $\mathrm{r}=-0.735)$, HBEBD fonksiyon skoru $(\mathrm{r}=-$ 0.497) ve HBEBD toplam skoru $(r=-0.689)$ arasında ise negatif yönde anlamlı ilişki bulundu (Tablo 3). "El bileği ekstansiyonu" ise el kavrama kuvveti ile pozitif yönde ( $\mathrm{r}=0.619), \mathrm{HBEBD}$ ağr skoru ( $\mathrm{r}=-0.525)$, HBEBD fonksiyon skoru $(\mathrm{r}=-$ $0.520)$ ve HBEBD toplam skorlar1 $(\mathrm{r}=-0.541)$ ile negatif yönde ve istatistiksel olarak anlamlı korelasyon gösterdi.

\begin{tabular}{|c|c|c|}
\hline & $\begin{array}{l}\text { Median (min - } \\
\text { maks) }\end{array}$ & $\begin{array}{c}\text { Çeyrekler } \\
\text { arası } \\
\text { uzaklık }\end{array}$ \\
\hline Preoperatif süre* (saat) & $139.2(45.5-816.0)$ & 177.5 \\
\hline Cerrahi süre (dk) & $135.0(55.0-260.0)$ & 67.5 \\
\hline \multicolumn{3}{|l|}{ Radyolojik Ölçümler } \\
\hline Radial inklinasyon $\left(^{\circ}\right)$ & $20.0(10.9-34.5)$ & 5.3 \\
\hline Radial uzunluk (mm) & $12.2(6.1-30.4)$ & 5.1 \\
\hline Ulnar varyans (mm) & $0.3(-3.8-9.5)$ & 3.3 \\
\hline Volar tilt $\left({ }^{\circ}\right)$ & $11.7(1.2-32.8)$ & 5.5 \\
\hline \multicolumn{3}{|l|}{ Fonksiyonel Ölçümler } \\
\hline EB fleksiyonu $(\%)^{ \pm}$ & $82.1(38.9-120.0)$ & 26.3 \\
\hline EB ekstansiyonu $(\%)^{ \pm}$ & $83.3(25.0-106.4)$ & 28.4 \\
\hline Ön kol supinasyonu $(\%)^{ \pm}$ & $100.0(64.4-100.0)$ & 2.2 \\
\hline Ön kol pronasyonu $(\%)^{ \pm}$ & $100.0(100.0-100.0)$ & 100.0 \\
\hline EB ulnar deviasyonu $(\%)^{ \pm}$ & $85.7(33.3-114.3)$ & 24.4 \\
\hline $\begin{array}{l}\text { EB radial deviasyonu } \\
(\%)^{ \pm}\end{array}$ & $87.5(42.9-150.0)$ & 31.7 \\
\hline El kavrama kuvveti $(\%)^{ \pm}$ & $66.7(27.3-100.0)$ & 37.8 \\
\hline HBEBD ağrı skoru & $9.0(0.0-38.0)$ & 11.0 \\
\hline HBEBD fonksiyon skoru & $3.5(0.0-17.0)$ & 10.0 \\
\hline HBEBD toplam skoru & $13.0(0.0-44.0)$ & 18.5 \\
\hline DASH skoru & $12.9(0.0-32.5)$ & 16.7 \\
\hline \multicolumn{3}{|c|}{$\begin{array}{l}\text { * Yaralanma tarihinden cerrahi tarihine kadar geçen süre } \\
\text { × Sağlam tarafa göre ölçülen yüzde değer } \\
\text { EB El Bileği, HBEBD Hasta Bazlı El Bileği Değerlendirmesi, } \\
\text { DASH Disabilities of Arm, Shoulder and Hand anketi, min } \\
\text { minimum, maks maksimum }\end{array}$} \\
\hline
\end{tabular}


Tablo 3. Hastaların Klinik Değerlendirme Parametreleri Arasındaki İlişki

\begin{tabular}{|c|c|c|c|c|c|c|c|c|c|}
\hline & $\begin{array}{c}\text { Ulnar } \\
\text { varyans } \\
\left(^{\circ}\right)\end{array}$ & $\begin{array}{c}\text { EB } \\
\text { fleksiyon } \\
\mathrm{u}(\%)^{ \pm}\end{array}$ & $\begin{array}{c}\text { EB } \\
\text { ekstansiyo } \\
\text { nu }(\%)^{ \pm}\end{array}$ & $\begin{array}{c}\text { Ön kol } \\
\text { supinasyon } \\
\mathrm{u}(\%)^{ \pm}\end{array}$ & $\begin{array}{c}\text { EB ulnar } \\
\text { deviasyo } \\
\text { nu }(\%)^{ \pm}\end{array}$ & $\begin{array}{c}\text { El kavrama } \\
\text { kuvveti } \\
(\%)^{ \pm}\end{array}$ & $\begin{array}{l}\text { HBEBD } \\
\text { ağr1 skoru }\end{array}$ & $\begin{array}{c}\text { HBEBD } \\
\text { toplam } \\
\text { skoru }\end{array}$ & DASH skoru \\
\hline Ulnar varyans $\left({ }^{\circ}\right)$ & -- & $\begin{array}{c}r=-0.324 \\
p=0.122\end{array}$ & $\begin{array}{l}r=-0.300 \\
p=0.154\end{array}$ & $\begin{array}{l}\mathrm{r}=0.023 \\
\mathrm{p}=0.915\end{array}$ & $\begin{array}{c}\mathrm{r}=-0.160 \\
0.454\end{array}$ & $\begin{array}{l}\mathrm{r}=-0.048 \\
\mathrm{p}=0.823\end{array}$ & $\begin{array}{c}\mathrm{r}=0.443^{*} \\
\mathrm{p}=0.030\end{array}$ & $\begin{array}{c}\mathrm{r}=0.424^{*} \\
\mathrm{p}=0.039\end{array}$ & $\begin{array}{l}\mathrm{r}=0.212 \\
\mathrm{p}=0.319\end{array}$ \\
\hline EB fleksiyonu $(\%)^{ \pm}$ & -- & -- & $\begin{array}{c}\mathrm{r}=0.553^{*} \\
\mathrm{p}=0.005\end{array}$ & $\begin{array}{l}\mathrm{r}=0.334 \\
\mathrm{p}=0.111\end{array}$ & $\begin{array}{c}\mathrm{r}=0.645^{*} \\
\mathrm{p}=0.001\end{array}$ & $\begin{array}{c}\mathrm{r}=0.660 * \\
\mathrm{p}<0.001\end{array}$ & $\begin{array}{c}r=-0.735^{*} \\
\mathrm{p}<0.001\end{array}$ & $\begin{array}{c}\mathrm{r}=-0.689^{*} \\
\mathrm{p}<0.001\end{array}$ & $\begin{array}{l}\mathrm{r}=-0.314 \\
\mathrm{p}=0.135\end{array}$ \\
\hline EB ekstansiyonu $(\%)^{ \pm}$ & -- & -- & -- & $\begin{array}{c}\mathrm{r}=0.714^{*} \\
\mathrm{p}<0.01\end{array}$ & $\begin{array}{c}\mathrm{r}=0.582^{*} \\
\mathrm{p}=0.003\end{array}$ & $\begin{array}{c}\mathrm{r}=0.619 * \\
\mathrm{p}=0.001\end{array}$ & $\begin{array}{c}\mathrm{r}=-0.525^{*} \\
\mathrm{p}=0.008\end{array}$ & $\begin{array}{c}\mathrm{r}=-0.541^{*} \\
\mathrm{p}=0.006\end{array}$ & $\begin{array}{c}r=-0.426^{*} \\
\mathrm{p}=0.038\end{array}$ \\
\hline Ön kol supinasyonu $(\%)^{ \pm}$ & -- & -- & -- & -- & $\begin{array}{l}r=0.400 \\
p=0.053\end{array}$ & $\begin{array}{l}r=0644^{*} \\
\mathrm{p}=0.001\end{array}$ & $\begin{array}{l}r=-0.395 \\
p=0.056\end{array}$ & $\begin{array}{l}r=-0.403 \\
p=0.051\end{array}$ & $\begin{array}{c}\mathrm{r}=-0.444^{*} \\
\mathrm{p}=0.030\end{array}$ \\
\hline EB ulnar deviasyonu $(\%)^{ \pm}$ & -- & -- & -- & -- & -- & $\begin{array}{c}\mathrm{r}=0.532 * \\
\mathrm{p}=0.007\end{array}$ & $\begin{array}{l}r=-0.333 \\
\mathrm{p}=0.112\end{array}$ & $\begin{array}{l}r=-0.327 \\
p=0.119\end{array}$ & $\begin{array}{l}r=-0.117 \\
p=0.586\end{array}$ \\
\hline El kavrama kuvveti $(\%)^{ \pm}$ & -- & -- & -- & -- & -- & -- & $\begin{array}{c}\mathrm{r}=-0.550^{*} \\
\mathrm{p}=0.005\end{array}$ & $\begin{array}{c}\mathrm{r}=-0.672 * \\
\mathrm{p}<0.001\end{array}$ & $\begin{array}{c}\mathrm{r}=-0.550 * \\
\mathrm{p}=0.005\end{array}$ \\
\hline HBEBD ağrı skoru & -- & -- & -- & -- & -- & -- & -- & $\begin{array}{c}\mathrm{r}=0.942 * \\
\mathrm{p}<0.001\end{array}$ & $\begin{array}{c}\mathrm{r}=0.591 * \\
\mathrm{p}=0.002\end{array}$ \\
\hline HBEBD toplam skoru & -- & -- & -- & -- & -- & -- & -- & -- & $\begin{array}{c}\mathrm{r}=0.746^{*} \\
\mathrm{p}<0.001\end{array}$ \\
\hline
\end{tabular}


Tablo 4. Grupların redüksiyon yeterliliğine göre ölçümlerinin karşılaştırılması

\begin{tabular}{|c|c|c|c|}
\hline & $\begin{array}{c}\text { Yetersiz Redüksiyon } \\
\text { Grubu (n=6) } \\
\text { Median (min-maks) }\end{array}$ & $\begin{array}{l}\text { Yeterli Redüksiyon } \\
\text { Grubu }(\mathrm{n}=\mathbf{2 5}) \\
\text { Median (min-maks) }\end{array}$ & p değeri \\
\hline \multicolumn{4}{|l|}{ Radyolojik Ölçümler } \\
\hline Radial inklinasyon $\left(^{\circ}\right)$ & $14.0(10.9-34.5)$ & $20.7(16.8-30.2)$ & $0.026 *$ \\
\hline Radial uzunluk (mm) & $9.7(6.1-18.1)$ & $13.2(10.2-30.4)$ & $0.022 *$ \\
\hline Ulnar varyans (mm) & $1.7(-1.7-9.5)$ & $0.0(-3.8-3.8)$ & 0.289 \\
\hline Volar tilt $\left({ }^{\circ}\right)$ & $13.3(5.0-32.8)$ & $12.0(6.3-18.5)$ & 0.887 \\
\hline \multicolumn{4}{|l|}{ Fonksiyonel Ölçümler } \\
\hline EB fleksiyonu $(\%)^{ \pm}$ & $71.4(38.9-89.6)$ & $82.1(46.7-120.0)$ & 0.297 \\
\hline EB ekstansiyonu $(\%)^{ \pm}$ & $76.1(57.8-86.2)$ & $87.5(25.0-106.4)$ & 0.235 \\
\hline Ön kol supinasyonu $(\%)^{ \pm}$ & $100.0(64.4-100.0)$ & $100.0(88.9-100.0)$ & 0.877 \\
\hline EB ulnar deviasyonu $(\%)^{ \pm}$ & $81.2(66.7-97.5)$ & $87.5(33.3-114.3)$ & 0.446 \\
\hline EB radial deviasyonu $(\%)^{ \pm}$ & $90.0(80.0-153.8)$ & $87.5(45.4-160.0)$ & 0.297 \\
\hline El kavrama kuvveti $(\%)^{ \pm}$ & $57.4(42.9-93.7)$ & $68.2(27.3-100.0)$ & 0.534 \\
\hline HBEBD ağrı skoru & $11.0(3.0-38.0)$ & $9.0(0.0-23.0)$ & 0.891 \\
\hline HBEBD fonksiyon skoru & $6.0(0.0-9.5)$ & $2.0(0.0-17.0)$ & 0.793 \\
\hline HBEBD toplam skoru & $14.5(3.0-44.0)$ & $13.0(0.0-40.0)$ & 0.534 \\
\hline DASH skoru & $12.9(1.7-30.0)$ & $10.3(0.0-32.5)$ & 0.629 \\
\hline
\end{tabular}

"Ön kol supinasyonu”nun da benzer şekilde hem kavrama kuvvetini ( $\mathrm{r}=0.644)$ hem de HBEBD fonksiyon skorunu ( $\mathrm{r}=-0.488)$ anlamlı etkilediği görüldü. DASH skorunun ise sadece el bileği ekstansiyon ve önkol supinasyon değerleri ile arasında anlamlı bir ilişki vardı (Tablo 3)."El kavrama kuvveti" değeri ile HBEBD ağrı skoru, HBEBD fonksiyon skoru, HBEBD toplam skoru ve DASH skoru arasinda negatif yönde anlamlı korelasyon tespit edildi (sirasiyla $\mathrm{r}=-0.638$; $\mathrm{r}=-$ $0.638 ; \mathrm{r}=-0.672 ; \mathrm{r}=-0.550)(\mathrm{p}<0.05)($ Tablo3).

Analizde hastalar redüksiyon yeterliliğine göre iki gruba ayrıldığında, gruplar arasında yalnızca radial inklinasyon açıları ve radial uzunluk değerlerinde anlamlı fark olduğu görüldü $(\mathrm{p}<0.05)$. Yetersiz redüksiyon olan grubun radial inklinasyon açıları ve radial uzunluk değerleri anlamlı olarak daha düşüktü (sırasıyla; $p=0.026$, $\mathrm{p}=0.022$ ). Bunun dişında iki grubun fonksiyonel ölçüm sonuçları arasında herhangi bir anlamlı fark saptanmadi ( $\mathrm{p}>0.05)$ (Tablo 4).

\section{Tartışma}

Çalışmada RDU kırığı sonrası volar plaklama cerrahisi yapılan ve fizyoterapi programın alınan 
hastaların radyolojik ölçümleri ile kavrama kuvveti, el bileği normal eklem hareketleri ve fonksiyonel sonuçları arasındaki ilişki araştırılmıştır. Sonuçlarımız radyolojik ölçümlerden yalnızca ulnar varyans değerinin fonksiyonel sonuçları etkilediğini, beklenenin aksine volar tilt, radial uzunluk ve radial inklinasyon açılarının ölçülen parametrelerin hiçbirinde etkili olmadığını göstermiştir. Ek olarak el bileği hareketlerindeki artışın, kavrama kuvvetini ve fonksiyonel sonuçları artırdığı belirlenmiştir.

Literatürde genel görüş olarak iyi bir anatomik redüksiyonun ve radyolojik sonuçların daha iyi fonksiyonel sonuçlara sebep olabileceği düşünülmekle birlikte çalışmaların sonuçları tartışmalıdır (15-17). Konuyla ilgili bazı çalışmalarda iyi anatomik sonuçlar ile fonksiyonel sonuçlar arasında doğrudan bir ilişki olduğu rapor edilirken (18), bazılarında radyolojik ölçümler ile fonksiyonel sonuçlar arasında herhangi bir ilişki olmadığ 1 gösterilmiştir (12, 21, 22). Konuyla ilgili Kumar ve ark. 2008 yılında yaptıkları çalışmada kapalı redüksiyon ve alçı ile fiksasyon yapılan 95 hastayı analiz etmişler ve radyolojik sonuçları kötü olan hastalarda bile iyi fonksiyonel sonuçlar elde edilebileceğini belirtmişlerdir (14). Jaremko ve ark. da benzer şekilde RDU kırı̆̆ı sonrası opere olmayan 74 hastada kötü radyolojik sonuçların DASH skorunu etkilemediğini göstermişlerdir (20).

RDU kırığg olan hastalarda iyi sonuçların göstergesi olarak hangi radyolojik ölçümün en iyi prediktör olduğuna dair literatürde fikir birliği bulunmamaktadır. Ancak normal volar tiltin sağlanmasının, karpal kemiklerin dizilimi ve el bileği fonksiyonları açısından oldukça önemli olduğu vurgulanmaktadır $(17,32)$. Karnezis ve ark. yaptıkları çalışmada, RDU kırığ 1 olan hastalarda volar tilt kaybı artıcça HBEBD içerisinde değerlendirilen ağrı skorunda da artış olduğunu ve volar tilt açılarının fonksiyonel sonuçlar kadar ağrı şiddetinde de etkili olabileceğini belirlemişlerdir (19). Çalışmamızda ise volar tilt değerinin fonksiyonel sonuçları etkilemediği, ancak radyolojik ölçümlerden sadece ulnar varyans değerinin ağrı skorları ve fonksiyonelliği etkilediği görülmüştür. $\mathrm{Bu}$ farklılığın nedeni kırık sonrası uygulanan redüksiyonların açık veya kapalı olması ile ilgili olabilir. Çünkü kapalı redüksiyonun 6-8 haftalık alçı ile immobilizasyon sürecinde eklem yapilarında meydana gelen olumsuz değişikliklerin miktarı ile erken harekete izin veren açık redüksiyonla volar plaklama yönteminin avantajları, fonksiyonel sonuçlar ve ağrı açısından farklılık yaratmaktadır.

Bazı araștırmalar opere olmayan RDU kırıklarında, redüksiyon öncesi yapılan radyolojik ölçümler arasında en önemli ölçümün radial kısalma olduğunu belirtmektedir $(33,34)$. Ancak redüksiyon öncesi yapılan radyolojik ölçümler ile fonksiyonel sonuçlar arasındaki ilişkiyi araştıran çalışmalarda çoğunlukla görülen, dorsal angulasyon değerinin fonksiyonel sonuçlarla korele olduğudur $(11,14,17)$. Çalışmamızda ise bu çalışmalardan farklı olarak RDU kırığ 1 sonrası volar plaklama yapılan hastaların postoperatif yapılan radyolojik ölçümleri değerlendirilmiş ve fonksiyonel ölçümlerle ilişkili tek değer ulnar varyans olmuştur. Dolayısıyla opere RDU kırıklarında fonksiyonel sonuçlar için en önemli radyolojik ölçümün ulnar varyans olduğu söylenebilir. Ancak bu görüşü güçlendirecek çalışmalara ihtiyaç vardır.

Chung ve ark. çalışmamıza benzer popülasyonda, RDU kırı̆̆ 1 sonrası açık redüksiyon internal fiksasyon yapılan hastalarda bu konuyu araştırmış ve sonuç olarak radyolojik ölçümler ile fonksiyonel sonuçlar arasında anlamlı ilişki bulmamışlardır (35). Yazarlar, çalışmaya alınan hastalar opere olduğundan dolayı radyolojik değerlerinin normal değerlere yakın olduğunu, bu sebeple analizlerinin kısıtlandığını belirtmişlerdir. Çalışmamızda da RDU kırığı sonrası opere olan hastalar alınmakla birlikte hastalarımızın radyolojik değerlerine bakıldığında minimum ve maksimum değerler arasındaki açıklığın yeterli genişlikte olduğu görülmüsstür. Buna rağmen ulnar varyans değeri dışındaki ölçümlerin fonksiyonel sonuçları etkilemediği belirlenmiştir. $\mathrm{Bu}$ durumun temel nedeni hastalara 12 hafta boyunca, haftada 2 gün süpervize fizyoterapi programının uygulanmış olması olabilir.

Wilcke ve ark. yaptıkları çalışmada radial inklinasyon değeri ile DASH skoru arasında 
anlamlı ilișki bulmuștur (11). Diğer benzer çalışmalarda da radial uzunluk kaybının kötü fonksiyonel sonuçlarla ilişkili olduğu bildirilmiştir $(36,37)$. Çalışmamızda hastaları redüksiyon yeterliliğine göre iki gruba ayırdığımızda, gruplar arasında radial inklinasyon ve radial uzunluk değerleri açısından anlamlı fark bulunmasına rağmen fonksiyonel sonuçlar açısından anlamlı fark bulunmamıştır. Sonuçlarımızın literatürdeki çalışmaların sonuçlarından farklı olmasının nedeni, diğer çalışmalarda hastaların opere olmamaları ve radyolojik ölçümlerinin postoperatif dönemde yapılmamış olması olabilir.

Çalışmamızda özürlülüğü ölçmek için kullanılan DASH skoru da radyolojik ölçümlerle ilişkili bulunmamıştır. Özürlülük ölçümleri subjektif ölçümlerdir ve asıl ölçülen hastaların algıladığ1 özürlülüktür. Hastaların algıladığ1 özürlülüğün birçok faktörden etkilendiği bilinmektedir. Radyolojik ölçümlerle belirlenen faktörler bunların yalnızca bir kısmını oluşturur (19, 35, 38). Ayrıca, radyolojik ölçümlerin yansıtmadığı diğer dokulardaki etkilenimler (yumuşak doku yaralanması ya da kıkırdak hasarı gibi) de hastaların özürlülük düzeyini etkileyebilmektedir. Çalışmamızda yapılan radyolojik ölçümlerin hiçbiri, yalnızca DASH skoru ile değil, kavrama kuvveti ve eklem hareket açıklıkları ile de anlamlı ilişki göstermemiştir. Teorik bilgi olarak normalin üzerindeki pozitif ulnar varyansın el bileği hareketlerini kısitlaması beklenmektedir (39). Çalışmamızda ulnar varyans fonksiyonel ağrı skorunu ve toplam skoru etkilerken, el bileği ve önkol hareketlerini etkilememiştir. $\mathrm{Bu}$ durumun nedeni pozitif ulnar varyansın ağrıda artışta, ağrının varlığının da fonksiyonel skorun toplam değerini kötüleştirmede önemli rol oynamasıdır.

Çalışmada fonksiyonel ölçümlerin kendi aralarındaki ilişkiler incelendiğinde ise el bileği ekstansiyon hareketinin tüm fonksiyonel ölçümlerle, el bileği fleksiyon hareketinin ise kavrama kuvveti ile güçlü bir ilişkisi olduğu belirlenmiştir. $\mathrm{Bu}$ istatistiksel sonuç, el bileği hareket kalitesinin kavrama başta olmak üzere üst ekstremite fonksiyonları için önemli bir role sahip olduğunu göstermiştir. Diğer taraftan önkol hareketleri, Karnezis ve arkadaşlarının çalışmalarında belirttikleri gibi (40) bizim çalışmamızda da ne fonksiyonel skorlara ne de kavrama kuvvetine etki etmiştir.

Çalışmanın örneklem büyüklüğünün azlığ 1 en önemli kısitlılıklarından biridir. Bunun nedenleri çalışmamızın 2 yıllık kesitsel çalışma olması, aynı ekip tarafindan volar plaklama yapılma zorunluluğu ve 12 haftalık fizyoterapi programına düzenli katılım şartı olarak düşünülebilir.

\section{Sonuç}

$\mathrm{Bu}$ çalışma RDU kırığı sonrası volar plaklama yapılan ve fizyoterapi programına alınan hastalarda, radyolojik ölçümlerden yalnızca ulnar varyans değerinin fonksiyonel sonuçları etkilediğini göstermiştir. Ayrıca el bileği hareketlerinin de kavrama kuvveti ve fonksiyonel skorları arttırmada önemli olduğu belirlenmiştir. Daha kesin sonuçlar için farklı redüksiyon tiplerinde ve farklı hasta sayılarında çalışmalara ihtiyaç bulunmaktadır.

\section{Teşekkür}

Biyoistatistiksel değerlendirmeye katkılarından dolayı Prof. Dr. Şerife Reyhan UÇKU'ya teşekkürlerimizi sunarız.

\section{Kaynaklar}

1. O'Neill TW, Cooper C, Finn JD, Lunt M, Purdie D, Reid DM, et al. Incidence of distal forearm fracture in British men and women. Osteoporosis international : a journal established as result of cooperation between the European Foundation for Osteoporosis and the National Osteoporosis Foundation of the USA. 2001;12(7):555-8.

2. Wakefield AE, McQueen MM. The role of physiotherapy and clinical predictors of outcome after fracture of the distal radius. The Journal of bone and joint surgery British volume. 2000;82(7):972-6.

3. Chung KC, Spilson SV. The frequency and epidemiology of hand and forearm fractures in the United States. The Journal of hand surgery. 2001;26(5):908-15.

4. Wiemer P, Koster G, Felderhoff J, Weber U. Frakturen am distalen Radius: Wandel der therapeutischen Strategien. Der Orthopäde. 1999;28(10):846-52.

5. Dekkers M, Soballe K. Activities and impairments in the early stage of rehabilitation after Colles' 
fracture. Disability and rehabilitation. 2004;26(11):662-8.

6. Hegeman JH, Oskam J, van der Palen J, Ten Duis HJ, Vierhout PA. The distal radial fracture in elderly women and the bone mineral density of the lumbar spine and hip. Journal of hand surgery (Edinburgh, Scotland). 2004;29(5):473-6.

7. Handoll HH, Madhok R, Howe TE. Rehabilitation for distal radial fractures in adults. The Cochrane database of systematic reviews. 2006(3):CD003324.

8. Valdes K, Naughton N, Michlovitz S. Therapist supervised clinic-based therapy versus instruction in a home program following distal radius fracture: a systematic review. Journal of hand therapy : official journal of the American Society of Hand Therapists. 2014;27(3):165-73; quiz 74.

9. Handoll HH, Madhok R. Conservative interventions for treating distal radial fractures in adults. The Cochrane database of systematic reviews. 2003(2):CD000314.

10.Sato K, Furumachi K, Nishida J, Tajima K, Kaiyama J, Suzuki Y, et al. Comparison of the volar locking plate and the bridging external fixator in the treatment of distal radius fracture based on range of wrist motion assessed by functional radiography. Medical Science Monitor. 2010;16(5):CR207-CR12.

11. Wilcke MK, Abbaszadegan H, Adolphson PY. Patient-perceived outcome after displaced distal radius fractures: a comparison between radiological parameters, objective physical variables, and the DASH score. Journal of Hand Therapy. 2007;20(4):290-9.

12.Bentohami A, Bijlsma T, Goslings J, de Reuver P, Kaufmann L, Schep N. Radiological criteria for acceptable reduction of extra-articular distal radial fractures are not predictive for patient-reported functional outcome. Journal of Hand Surgery (European Volume). 2013;38(5):524-9.

13.Shauver MJ, Chang KW-C, Chung KC. Contribution of functional parameters to patientrated outcomes after surgical treatment of distal radius fractures. The Journal of hand surgery. 2014;39(3):436-42.

14.Kumar S, Penematsa S, Sadri M, Deshmukh SC. Can radiological results be surrogate markers of functional outcome in distal radial extra-articular fractures? International orthopaedics. 2008;32(4):505-9.

15.Smilovic J, Bilic R. Conservative treatment of extra-articular Colles' type fractures of the distal radius: prospective study. Croatian medical journal. 2003;44(6):740-5.

16. Broos P, Fourneau I, Stoffelen D. Fractures of the distal radius. Current concepts for treatment. Acta orthopaedica belgica. 2001;67(3):211-8.

17. Gliatis J, Plessas S, Davis T. Outcome of distal radial fractures in young adults. Journal of Hand Surgery. 2000;25(6):535-43.

18. Stewart HD, Innes AR, Burke FD. Factors affecting the outcome of Colles' fracture: an anatomical and functional study. Injury. 1985;16(5):289-95.

19.Karnezis I, Panagiotopoulos E, Tyllianakis M, Megas P, Lambiris E. Correlation between radiological parameters and patient-rated wrist dysfunction following fractures of the distal radius. Injury. 2005;36(12):1435-9.

20.Jaremko J, Lambert R, Rowe B, Johnson J, Majumdar S. Do radiographic indices of distal radius fracture reduction predict outcomes in older adults receiving conservative treatment? Clinical radiology. 2007;62(1):65-72.

21.Young C, Nanu A, Checketts R. Seven-year outcome following Colles' type distal radial fracture. A comparison of two treatment methods. Journal of Hand Surgery. 2003;28(5):405-8.

22. Young BT, Rayan GM. Outcome following nonoperative treatment of displaced distal radius fractures in low-demand patients older than 60 years. The Journal of hand surgery. 2000;25(1):1928.

23. MacDermid JC, Turgeon T, Richards RS, Beadle M, Roth JH. Patient rating of wrist pain and disability: a reliable and valid measurement tool. Journal of orthopaedic trauma. 1998;12(8):577-86.

24.Ozturk O, Sari Z, Ozgul B, Tasyikan L. Validity and reliability of the Turkish "Patient-Rated Wrist Evaluation" questionnaire. Acta orthopaedica et traumatologica turcica. 2015;49(2):120-5.

25.Hudak PL, Amadio PC, Bombardier C. Development of an upper extremity outcome measure: the DASH (disabilities of the arm, shoulder and hand) [corrected]. The Upper Extremity Collaborative Group (UECG). American journal of industrial medicine. 1996;29(6):602-8.

26.Düger T, Yakut E, Öksüz Ç, Yörükan S, Bilgütay BS, Ayhan Ç, et al. Kol, Omuz ve El Sorunları (Disabilities of the Arm, Shoulder and Hand DASH) Anketi Türkçe uyarlamasının güvenirliği ve geçerliği. Fizyoter Rehabil. 2006;17(3):99-107.

27. Shechtman O, Gestewitz L, Kimble C. Reliability and validity of the DynEx dynamometer. Journal of Hand Therapy. 2005;18(3):339-47. 
28.Budziareck MB, Pureza Duarte RR, Barbosa-Silva MC. Reference values and determinants for handgrip strength in healthy subjects. Clinical nutrition (Edinburgh, Scotland). 2008;27(3):35762.

29.Green DP. Rockwood and Green's fractures in adults: Lippincott Williams \& Wilkins; 2010.

30.Ruedi TP, Buckley R. AO principles of fracture management Vol 2 specific fractures: New York: Thieme, 2007; 2007.

31.Nana AD, Joshi A, Lichtman DM. Plating of the distal radius. Journal of the American Academy of Orthopaedic Surgeons. 2005;13(3):159-71.

32.McQueen M, Hajducka C. Redisplaced unstable fractures of the distal radius. Bone \& Joint Journal. 1996;78(3):404-9.

33.Dixon S, Allen P, Bannister G. Which Colles' fractures should be manipulated? Injury. 2005;36(1):81-3.

34.McQueen M, Caspers J. Colles fracture: does the anatomical result affect the final function? Bone \& Joint Journal. 1988;70(4):649-51.

35.Chung KC, Kotsis SV, Kim HM. Predictors of functional outcomes after surgical treatment of distal radius fractures. The Journal of hand surgery. 2007;32(1):76-83.

36.Hove LM, Fjeldsgaard K, Skjeie R, Solheim E. Anatomical and functional results five years after remanipulated Colles' fractures. Scandinavian journal of plastic and reconstructive surgery and hand surgery. 1995;29(4):349-55.

37.Villar R, Marsh D, Rushton N, Greatorex R. Three years after Colles' fracture. A prospective review. Bone \& Joint Journal. 1987;69(4):635-8.

38.Forward D, Sithole J, Davis T. The internal consistency and validity of the Patient Evaluation Measure for outcomes assessment in distal radius fractures. The Journal of Hand Surgery: European Volume. 2007;32(3):262-7.

39.Sammer DM, Rizzo M. Ulnar impaction. Hand clinics. 2010;26(4):549-57.

40.Karnezis I, Fragkiadakis E. Association between objective clinical variables and patient-rated disability of the wrist. Bone \& Joint Journal. 2002;84(7):967-70. 